\section{EMBRYRIDDLE}

Aeronautical University

SCHOLARLY COMMONS
Journal of Aviation/Aerospace

Education \& Research

Volume 21

Number 3 JAAER Spring 2012

Article 4

Spring 2012

\title{
Mixed Methods Study of Demand Determinants of Airline Coach and Saddle Seats
}

Kelly Whealan George

Follow this and additional works at: https://commons.erau.edu/jaaer

\section{Scholarly Commons Citation}

George, K. W. (2012). Mixed Methods Study of Demand Determinants of Airline Coach and Saddle Seats. Journal of Aviation/Aerospace Education \& Research, 21(3). https://doi.org/10.15394/jaaer.2012.1322

This Article is brought to you for free and open access by the Journals at Scholarly Commons. It has been accepted for inclusion in Journal of Aviation/Aerospace Education \& Research by an authorized administrator of Scholarly Commons. For more information, please contact commons@erau.edu. 


\title{
MIXED METHODS STUDY OF DEMAND DETERMINANTS OF AIRLINE COACH ANS SADDLE SEATS
}

\author{
Kelly Whealan George
}

\section{Introduction}

The SkyRider seat was presented in September 2010 at the Aircraft Interiors Expo in California as a potential strategy to decrease space between seat rows and increase the revenue generating capacity of an airline. Many airlines already raise revenue with differential pricing to customers on seat widths, legroom, seat location, and seat choice. This mixed-seating methods exploratory study seeks to identify what factors passengers consider when faced with selecting a traditional seat or a saddle seat for a short-haul flight. A saddle seat is significantly different from current airline seats, designed with minimal amenities, including a hook to hang a jacket or bag and a shelf for another car carry-on. Additionally, how much an airfare would need to be reduced compared to regular airline seats to entice purchase of the saddle seat instead of a contemporary padded, reclining seat with upwards of 30 inches of legroom typical of an airline's economy class? The sequential phase of the study did not yield any emergent research questions from phase one. Subsequently, the conjoint analysis determined what attributes of the SkyRider seat that were most influential to their choice in airline seats.

Although the saddle seat has not been certified by the European and American aviation authorities that have stringent requirements on structural seat performance and emergency egress, numerous airlines have expressed interest in the seat expecting future certification as they pursue more flying revenue per plane (Jones, 2010). An airplane's seat configuration could be adjusted to increase the number of paying passengers per flight as much as $40 \%$. If an airline could increase its revenue by using SkyRider seats, the economic benefit could promote adoption by at least the low cost airlines or any airlines with short haul flights. Additional costs will include additional weight, fuel, baggage handling, aircraft modifications, and operational policies.

\section{Method}

\section{Mixed Method Research Design}

To explore passenger's demand determinants of saddle seats and the impact of an expected price discount for passengers, a sequential exploratory mixed design was chosen (exploratory qual $\rightarrow$ QUAN + QUAL is depicted in Figure 1). The mixed methods, two-phase design research began with an exploratory qualitative phase. The primary purpose of phase one was to identify attributes of the saddle seat to direct the development of the second phase quantitative and qualitative instrument. The research applied a constructivist viewpoint to gather multiple perspectives and a more thorough understanding of the consumer (Teddlie \& Tashakkori, 2007). Based on the information from in the first phase of the study, we adopted a pragmatist approach in the second phase (Morgan, 2007). The a priori hypothesis was that at a minimum, price and comfort would be major categories of attributes for the saddle seat. 


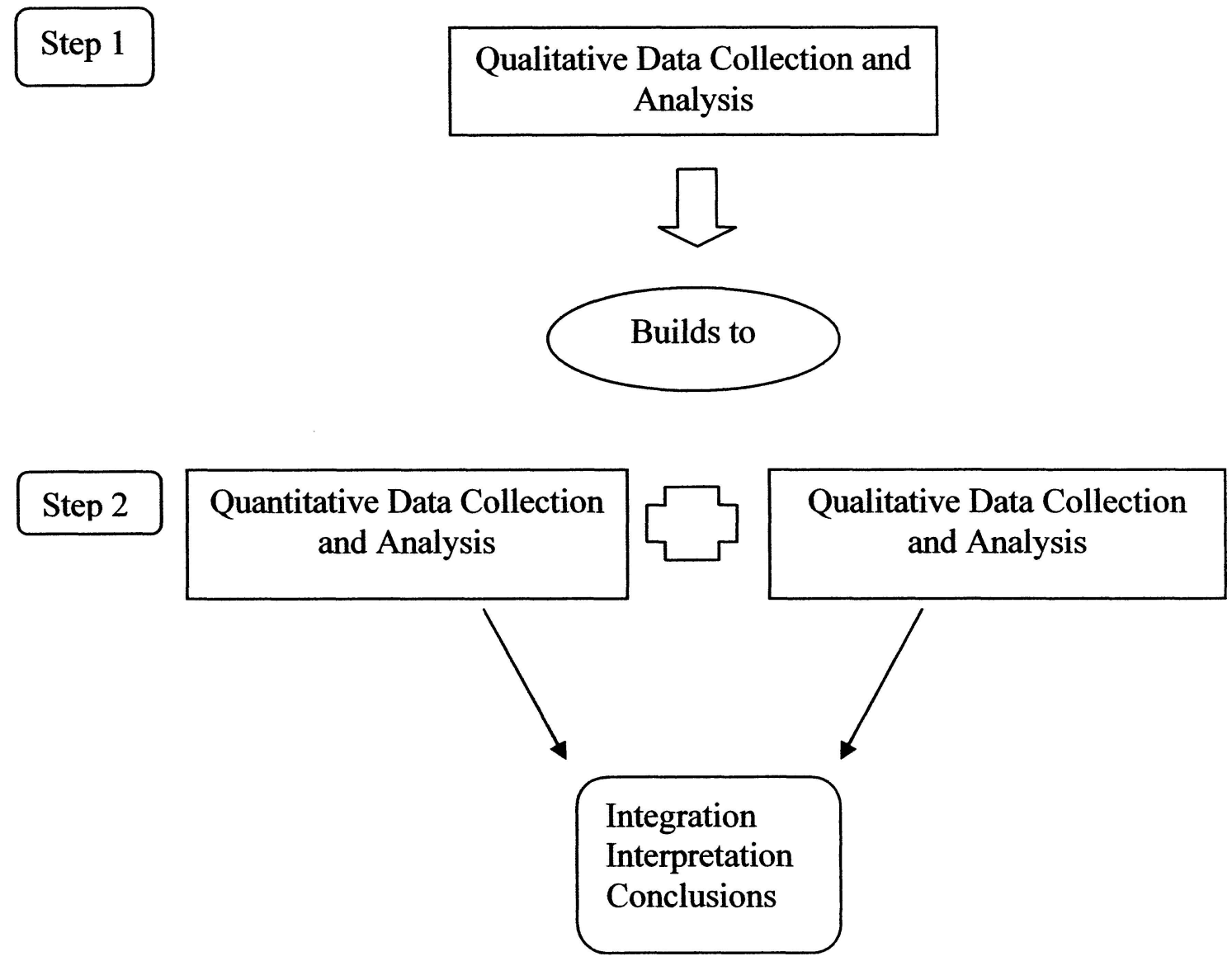

Figure 1. Flowchart of the Basic Procedures in Implementing an Exploratory Design

The initial exploratory questions sought to determine price and non-price factors, under which potential customers would consider the saddle seat and to aid in development of a survey instrument. Respondents were asked if they traveled for work, leisure, or both. Respondents were also asked who paid for their flights: employer, self, or other, in an attempt to determine if demand depended on the purpose of travel or who bought the seat. Participants were shown the picture of the saddle seat in Figure 2 that was retrieved from the manufacturer's website as the only description of the seat. Since consumers are motivated by things other than price, questions with opened ended responses attempted to identify whether or not consumers will even entertain the option of the saddle seat and what concerns or demands consumers will place upon the airline. Open ended questions were constructed so as not to lead the respondent to specific topics or responses (Babbie 2010). The qualitative data analysis was intended to be inductive to determine emerging themes for further research. 


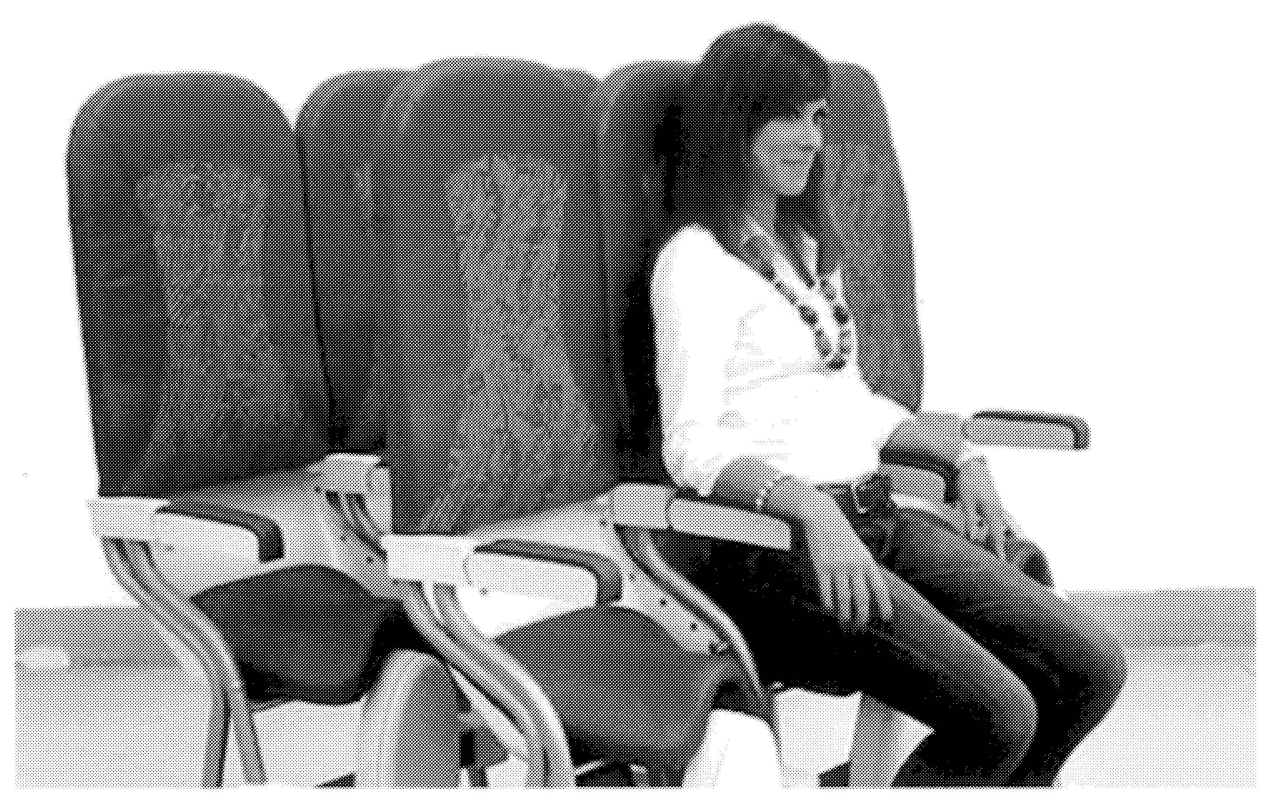

Figure 2. The new "saddle seat" designed by Aviointeriors.

Qualitative data was analyzed for common attributes as a list of demand determinants of the saddle seat for airline passengers. From this list, a survey was developed for phase two that asks potential airline passengers to rank their preferences on attributes and their conditions to agree to a saddle seat.

The categories from phase one guided the development of attributes to include in phase two for a conjoint analysis. The conjoint analysis of the SkyRider seat using information gathered in phase one examined the influence of three factors on consumer preference; price, duration of flight, and location of seat in airplane. Conjoint analysis yielded a part-worth value or utility score for each attribute level. The utility score represented a measure of preference level for each attribute level with higher scores reflecting higher value of the attribute level. Each presented selection had a total utility measure for that combination of attributes and attribute levels allowing for predicting preferences of an attribute.

An open-ended question was also asked in phase two to gather any additional information respondents would like to note. Integration of the data is expected to take place, if at all, in the conclusions of the research. The flowchart of the basic two-phase, exploratory mixed methods research design is shown in Figure 3. 


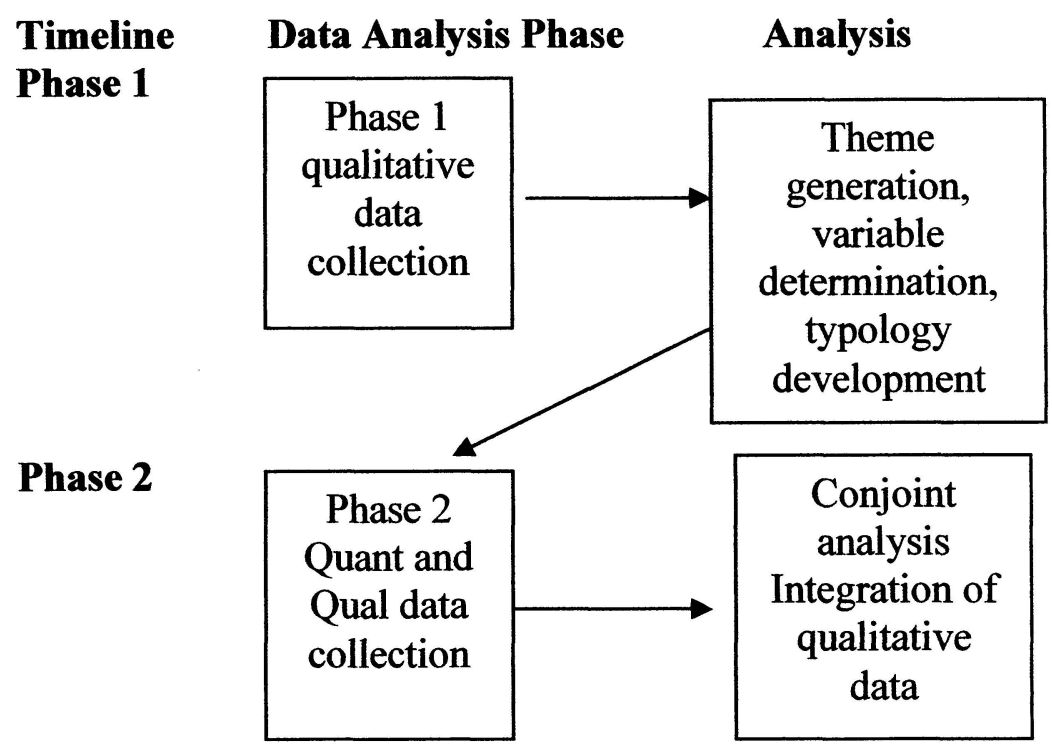

Figure 3. Data analysis procedures for a two phase exploratory instrument design mixed methods study.

\section{Participants}

With such a short time frame for the research compared to a full dissertation study, sampling for both phases were a convenience sample. Sample participants were required to be part of the commercial flying public and have flown at least twice in the past year for either business and/or leisure purposes. Phase one and phase two surveys were delivered via Survey Monkey using email addresses from the researchers personal and business contacts. Phase one sample included non-senior citizen leisure only travelers, middle aged business and leisure travelers, and older leisure only travelers in an attempt to get views from airline passengers that span those customers that purchase seats based on price to those travelers that take comfort, scheduling and other airline factors into consideration. Surveys were sent to ten individuals and seven responded. Phase two participants were also a convenience sample of fifty seven respondents gathered from personal and business contacts of the researcher. Phase two participants were limited to leisure only travelers as the project was limited in scope based on the results from phase one.

\section{Results}

Phase One Qualitative Data Analysis

The analysis for Phase One served to determine which attributes of an airline seat are important to potential passengers. Attributes were identified using suggestions from respondents without leading from classmates in the discussion board of the fall term of Ph.D in aviation class DAV 723 at Embry-Riddle Aeronautical University (ERAU). This data was collected via Survey Monkey and answers to open-ended qualitative questions were then coded into general categories or units of information (UOI) of the participant responses. No sub-categories emerged in 
this small sample; however, there was an indication that in a broader study, a subcategory of seat location could emerge.

All respondents reported that they consider different seating options when choosing flights and all but one would not consider the SkyRider saddle seat when shown a picture of the seat, even if a price discount was offered. Of the seven respondents, five reported traveling only for leisure and personally paying for their flights; one reported traveling for business and having the employer pay for their flights; and one reported traveling for leisure and work. Four of the seven respondents reported they travel at least two times a year. Attributes that respondents indicated they currently considered when choosing a seat, in order of importance based on number of mentions, were location in the airplane to include both row location and aisle, window, or middle seat; comfort of the seat to include legroom, armrests, proximity to other passengers; and lastly, price.

Contrary to the respondents' prior claims that a price discount for the SkyRider seat would not entice them to consider it as a viable option, four respondents answered that they would consider a price discount. Respondents' requirements for a price discount ranged from $20 \%$ to $75 \%$, with a mean of $45 \%$ from a comparable price for a regular seat while one respondent noted the flight must cost less than $\$ 100$ and one respondent would only fly it for free or leisure. Additionally, two respondents noted that other considerations would be the duration of the flight (less than one hour) and the location of the seat (proximity to other passengers).

There was one extreme case that could not be ignored as a theme that may be indicative of a sector of the population not fully represented in a convenience sample. The extreme case provided information that the respondent would not entertain the SkyRider seat if flying for business but would entertain this seating option if flying for leisure. This highlights that there may be very different considerations of seat attributes based on the passenger's purpose of flying and who is paying for the ticket that was beyond the scope of this project but an area for further research. Because of this lone extreme case, phase two data collection and analysis was limited to only leisure travel.

Phase Two Quantitative and Qualitative Data Analysis

The categories from phase one guided the development of attributes and levels for a quantitative instrument designed to deliver the data for a conjoint analysis for phase two. The conjoint analysis of the SkyRider seat used information gathered in phase one and examined the influence of three factors on consumer preference; price, duration of flight, and location of seat in airplane. There are two levels for seat choice, standard or saddle; two levels for price, regularly expected price or a $45 \%$ discount; two levels for duration of flight, one or three hours; and two levels for location of the seat, passenger's choice or no choice. The respondents were asked to rank the various choices based on trading off different features against others. Conjoint analysis determined the relative importance of each attribute as well as which levels of each attribute are most preferred (PASW Conjoint 18.) The factors seat style, price, duration of flight, and seat choice were the dependent variables that respondents worked with using the ranking system.

Using the PAWS software program, conjoint analysis resulted in the utility values presented in Table 1. The syntax for the conjoint analysis is located in appendix three. There is an inverse relationship between the utility values and the saddle seat, price, flight duration and no seat choice. The range of importance values factors presented in Table 2 reflect how important each attribute was to the respondents. Importance values sum to 100 . Seat type was the most important attribute to respondents, followed by price, flight duration, and seat choice in order of importance. Pearson's R indicating the correlation between the observed and predicted preferences was $.982, \rho \geq .000$. 
Journal of Aviation/A erospace Education \& Research, Vol. 21, No. 3 [2012], Art. 4

Demand Determinants of Airline Coach and Saddle Seats

Table 1

Utility values for attributes and levels

\begin{tabular}{llcc}
\hline Attributes & Levels of Attribute & Utility Estimate & Standard Error \\
\hline Seat type & Standard coach seat & 1.272 & .166 \\
& Saddle seat & -1.272 & .166 \\
Price & Normal price & -.842 & .166 \\
& 45\% discount & .842 & .166 \\
duration & 1 hour & .516 & .166 \\
& 3 hours & -.516 & .166 \\
Seat location & Assigned - no choice & -.130 & .166 \\
& Choice & .130 & .166 \\
\hline
\end{tabular}

Table 2

Importance values of attributes

\begin{tabular}{lc}
\hline Attribute & Importance Value \\
\hline Seat type & 46.063 \\
Price & 30.512 \\
Duration & 18.701 \\
Seat location & 4.724 \\
\hline
\end{tabular}

The qualitative data from phase two was analyzed to see if responses enhance, confirm, or disagree with conclusions drawn from the quantitative inferential data analysis. Qualitative themes were sorted by themes. Of the 57 respondents, 28 provided additional comments regarding the survey. Common themes that emerged from the responses, ranked in order of most mentioned to least mentioned, were saddle seat comfort, duration of flight, price, physical size of passenger and proximity to other passengers, safety issues of the saddle seat and other. The other category included responses about the inadequateness of the options presented and some disparaging comments about the saddle seat picture presented in the survey.

\section{Discussion}

During phase one, respondents indicated that the attributes important to their future possible consideration of the SkyRider saddle seat are price, duration of flight, and location of the seat in the plane. Respondents had indicated that seat comfort was a current consideration of passengers for choice of seat, but once the picture of the SkyRider saddle seat were shown to respondents, comfort was not a factor in any future discussion of seat considerations.

The quantitative data from phase one was analyzed to answer the initial research question, "how much of an airfare discount does the airline need to offer compared to regular airline seats in order to entice customers to purchase the saddle seat for a short-haul flight?" Respondents'

requirements for a price discount ranged from 20 to $75 \%$, with a mean of $45 \%$ from a comparable price for a regular seat while one respondent noted the flight must cost less than $\$ 100$ and one respondent would only fly it for free for leisure. Since this would represent a drastic cut in revenue for the airlines, airlines attempting to use the saddle seat would have to consider a thorough cost benefit analysis to investigate if the additional fixed upfront costs of equipping their plane with the SkyRider seat and any additional variable costs would be compensated by additional revenue brought on by the SkyRider seat.

Part-worth or utility values displayed in Table 1 show the trade-offs that respondents made with respect to each value. As expected, respondents valued the standard coach seat versus the saddle seat; a $45 \%$ discounted price versus normal fare; a one hour flight versus a three hour flight; and seat choice versus no seat choice. The results show that seat type was the most influential on overall preference. Price was the next most influential attribute to respondents followed by flight duration and whether or not the respondent can choose their seat, in that respective order.

The qualitative data collected in phase two expanded on the themes generated by phase one qualitative data as well as confirming and expanding the conclusions reached by the conjoint analysis conducted in phase two. Qualitative responses reinforced the quantitative results quite well. The biggest attribute of valuation for respondents 
was seat type. Respondents were very quick to identify that that saddle seat looked extremely uncomfortable and that the picture was not representative of a fully-loaded airplane with bigger individuals sitting next to each other on a saddle seat. Following this, the price theme was noted as some respondents expressed that if the price was a good enough deal and combined with a short flight, they would entertain a saddle seat. Mentions of seat safety, both FAA certified and the perceived increased risk of deep vein thrombosis, emerged during phase two that did not emerge in phase one of the study. However, in the conception of this study, the saddle seat's affect on passenger health was identified.

Limitations

Simple conjoint analysis does not allow for interactions between one level of an attribute with another level of an attribute and was not taken into consideration in this analysis. Interactions can be included in the analysis but that was beyond the scope of this project. There were no holdout cases from the sample that would not be used to build the preference outputs but would be compared to the results and would test the validity of the results.

The sample was only a convenience sample of 57 responses and not representative of the breakdown of the flying public. However, Akaah and Korganonkar (1988) noted that a sample size of less than 100 is sufficient for a reliable conjoint analysis even though commercial conjoint study samples typically range from 100 to 1000 which is a large range to choose from.

Responses from the qualitative phase two of the survey indicated that respondents did not like the response mechanism for ranking preferences. Respondents noted either they did not understand what to do, they did not like the choices offered so omitted ranking a choice, and had trouble ranking between eight choices. A different survey design whereby respondents opt to choose first, second, third....eight, may have yielded more accurate results.
Demographic data of respondents was not collected so the impact of age or other demgraphic factors was not addressed.

\section{Conclusion}

The SkyRider seat was presented in September 2010 at the Aircraft Interiors Expo in California as a strategy to decrease space between seat rows and increase the revenue generating capacity of an airline. This mixed methods exploratory study identified four additional factors or attributes passengers would consider when faced with a choice of a traditional seat or a saddle seat for a short-haul flight. These four factors were seat choice, price, flight duration and location of the seat. The survey also indicated that on average, a $45 \%$ discount from what passengers would normally expect to pay would be an enticement to get passengers to purchase a saddle seat.

Despite the absence of certification for commercial flights by the European and American aviation authorities, numerous airlines have expressed interest in the seat however a thorough cost benefit analysis has not been published. For airlines to pursue incorporating this seating option into their seat configuration, there will be additional costs to consider to determine if the additional revenue warrants the investment into saddle seats. This study indicates that there is a potential market for this seat, specifically short flights where the passenger ranks price as the deciding determinant of their choice. However, comfort and safety issues will need to be addressed by airlines with the saddle seat. Twenty years ago, such a seat probably would have gotten laughs. However, with a continuing trend to airlines providing fewer amenities, increased baggage costs, paying for exit row seats or assigned seats, no complimentary food or drink, and even paying to use the lavatory, the saddle seat may find a home in a low-cost airline.t 
Kelly Whealan George graduated with a BBA in Finance from Southern Methodist University. She worked as a banking officer at Bank of American (formerly NCNB Texas) for two years. While completing her Masters in Economics at Southern Methodist University, she began work as an economist at the Federal Reserve Bank in Dallas. Her areas of research include international trade and the North American Free Trade Agreement, corporate banking finance, the aviation, agriculture, petroleum and services industries, national income distribution, and educational economics. Mrs. Whealan George published several articles in professional journals and is currently enrolled in the inaugural class of ERAU's Ph.D. in Aviation.

Ms. Whealan George serves as executive director of research administration and discipline chair of the Social Sciences and Economics program in the department of Arts and Sciences at ERAUWolrdwide. She is also instrumental in the development and implementation of ERAU Worldwide's Assessment Program. SHecurrently teaches Economics and Statistics courses for ERAU Worldwide. 


\section{References}

Akaah, I.P. \& Korgaonkar, P.K. (1988). A conjoint investigation of the relative importance of risk relievers in direct marketing. Journal of Advertising Research, 28:4, 38-44.

American Psychological Association. (2010). Publication manual of the American Psychological Association (6th ed.). Washington, DC: Author.

Babbie, E. (2010). The practice of social research (12 ${ }^{\text {th }}$ ed.). Belmont, CA: Wadworth Cengage Learning.

Creswell, J. W., \& Plano Clark, V. L. (2010). Designing and conducting mixed methods research (2nd ed.). Thousand Oaks, CA: Sage Publications.

International Business Machines. (IBM). (2009). PASW Statistics GradPack (Version 18.0) (Computer Software). Chicago, IL: SPSS.

Jones, C. (2010, September 10). SkyRider airline seat packs passengers into 23 inches of space. USA Today. pp. C-1. PASW Conjoint 18. SPSS Statistics Guide to Data Analysis for PASW Statistics 18. Prentice Hall. Retrieved from http://support.spss.com/productsext/statistics/documentation/18/client/User\%20Manuals/English/PASW\%20Conjoin t\%2018.pdf

Teddlie, C. B., \& Tashakkori, A. (2009). Foundations of mixed methods research: Integrating quantitative and qualitative approaches in the social and behavioral sciences. Thousand Oaks, CA: Sage Publications. 


\section{Appendix A}

Do you travel mostly for

Business

Leisure

Mixed

\#1. Do you travel at least 2 times a year on flights not greater than 3 hours in duration. Yes

No

\#2. Who typically pays for your flights? work

self

other

\#3. Would you consider a saddle seat for a short-haul (less than 3 hours) flight?

Yes

No

Not sure

\#4. Do/Would you consider different seat options available on your flights?

Yes

No

\#5. What factors do/would you take into consideration when determining what type of airline seat to purchase (open reply, required to answer)

[IMAGE OF SKY RIDER SEAT SHOWN TO RESPONDENT HERE]

\#6. Would you consider choosing to fly on a flight less than 3 hours in duration in a SkyRider saddle seat shown in the image above?

Yes

No

(If you answer to \#6 was yes, please select N/A and move to question \#8)

\#7. If your answer to \#6 was no, would a price discount change your mind?

Yes

No

N/A

\#8. If you answer to \#6 was yes, please list the factors or conditions under which you would consider purchasing the SkyRider seat instead of your usual airline seat choice.

(open reply, required to answer)

\#9. What percentage off of the fare you normally would expect to pay for a standard airline seat would entice you to choose to fly in a SkyRider saddle seat?

(open reply, required to answer) 


\section{Appendix B - Phase Two Data Collection Instrument}

1. Consider the time you travel for leisure. Please rank the following seat options using the pictures shown above for standard coach and saddle seats according to your preference. Seat choice refers to both row location and window, aisle, or middle seating.

\begin{tabular}{|c|c|c|c|c|c|c|c|c|}
\hline & $\begin{array}{l}\text { Most } \\
\text { preferred }\end{array}$ & $\begin{array}{l}2^{\text {nd }} \\
\text { choice }\end{array}$ & $\begin{array}{l}3^{\text {rd }} \\
\text { choice }\end{array}$ & $\begin{array}{l}4^{\text {th }} \\
\text { choice }\end{array}$ & $\begin{array}{l}5^{\text {th }} \\
\text { choice }\end{array}$ & $6^{\text {th }}$ choice & $7^{\text {th }}$ choice & $\begin{array}{l}\text { Least } \\
\text { preferred }\end{array}$ \\
\hline $\begin{array}{l}\text { Saddle seat, normal } \\
\text { price, } 3 \text { hour flight, } \\
\text { seat choice }\end{array}$ & & & & & & & & \\
\hline $\begin{array}{l}\text { Saddle seat, } 45 \% \text { off } \\
\text { price, } 3 \text { hour flight, } \\
\text { no choice }\end{array}$ & & & & & & & & \\
\hline $\begin{array}{l}\text { Standard seat, } 45 \% \\
\text { off price, } 3 \text { hour } \\
\text { flight, no seat choice }\end{array}$ & & & & & & & & \\
\hline $\begin{array}{l}\text { Saddle seat, normal } \\
\text { price, } 1 \text { hour flight, } \\
\text { no seat choice }\end{array}$ & & & & & & & & \\
\hline $\begin{array}{l}\text { Standard seat, normal } \\
\text { price, } 1 \text { hour flight, } \\
\text { no seat choice }\end{array}$ & & & & & & & & \\
\hline $\begin{array}{l}\text { Standard seat, } 45 \% \\
\text { off price, } 1 \text { hour } \\
\text { flight, seat choice }\end{array}$ & & & & & & & & \\
\hline $\begin{array}{l}\text { Saddle seat, } 45 \% \text { off } \\
\text { price, } 1 \text { hour flight, } \\
\text { seat choice }\end{array}$ & & & & & & & & \\
\hline $\begin{array}{l}\text { Standard seat, } \\
\text { normal price, } 3 \text { hour } \\
\text { flight, seat choice }\end{array}$ & & & & & & & & \\
\hline
\end{tabular}

2. Anything else you would like to add to your response.

3. Name, City, State 


\section{Appendix C - Conjoint Syntax}

\section{GET DATA}

$/ \mathrm{TYPE}=\mathrm{XLS}$

/FILE $=$ 'C:IUsers $\backslash$ Tony $\backslash$ Documents|KellysData4SPSS.xls'

/SHEET=name 'Sheet1'

/CELLRANGE=full

/READNAMES $=$ on

/ASSUMEDSTRWIDTH $=32767$.

DATASET NAME DataSet2 WINDOW=FRONT.

DATASET ACTIVATE DataSet2.

DATASET CLOSE DataSet1.

SAVE OUTFILE $=$ 'C:IUsers $\mid$ Tony $\backslash$ Documents $\backslash$ saddletestdata.sav'

/COMPRESSED.

GET

FILE='C:IUsers|TonylDocuments|saddle4X2.sav'.

DATASET NAME DataSet3 WINDOW=FRONT.

DATASET ACTIVATE DataSet3.

DATASET CLOSE DataSet2.

conjoint plan $=* /$ data $=$ 'C:IUsers $\backslash$ Tony $\backslash$ Documents $/$ saddletestdata.sav'

$/$ RANK $=$ rank1 to rank8. 
Introduction to the Wright Brothers papers by Tim Brady, Ph.D.; Dean, College of Aviation, EmbryRiddle Aeronautical University -Daytona Beach:

Even though the events surrounding the law suits brought by the Wright brothers against those aircraft manufacturers (or would-be manufacturers) for patent infringement happened more than a hundred years ago, debates still occur on the issues. These two papers provide excellent discussions from two different points of view. Together, they frame the issues splendidly. 
Journal of Aviation/Aerospace Education \& Research, Vol. 21, No. 3 [2012], Art. 4

https://commons.erau.edu/jaaer/vol21/iss3/4 